\title{
LAS LITERATURAS DE LO INSÓLITO. UNA TIPOLOGÍA
}

\author{
POR \\ Carlos Abraham \\ Universidad Nacional de La Plata
}

El establecimiento de una definición convincente de géneros como la ciencia ficción o la literatura fantástica es un objetivo buscado desde hace tiempo en la teoría literaria. Sin embargo, no se han propuesto tipologías que sean lo bastante descriptivas de su objeto de estudio como para resultar una herramienta útil para el investigador. El principal defecto de las tipologías existentes es que suelen concentrarse en un único género (por ejemplo, la literatura fantástica), dejando desatendidos los géneros vecinos. Por un lado, eso genera la tendencia a acumular rasgos y funciones de los géneros cercanos al estudiado: la consecuencia es que la tipología pierde poder descriptivo y se hunde en la confusión conceptual. Por otro, causa un aislamiento artificial del género analizado, separándolo del conjunto de los géneros afines. Pero además, impide el establecimiento de pautas precisas y claras que permitan distinguir dichos géneros. Así, creo necesario el establecimiento de una tipología integrada, que describa su objeto de estudio de modo coherente y desde ángulos múltiples. Es por ello que no he titulado este ensayo "La ciencia ficción" o "La literatura fantástica" sino "Las literaturas de lo insólito".

Defino las literaturas de lo insólito como el conjunto de los géneros literarios caracterizados por presentar elementos y situaciones inexistentes en el mundo real, o tan inusuales que su condición de realidad puede, sin excesivo esfuerzo, ser puesta en duda. En este sentido, se oponen a las literaturas de lo normal, que presentan elementos y situaciones existentes en el mundo real, y lo suficientemente usuales para que su condición de realidad no pueda ser puesta en duda. Los géneros pertenecientes a la primera categoría son la literatura fantástica, la ciencia ficción, la literatura maravillosa y la literatura de lo extraño. Los pertenecientes a la segunda son numerosos: la literatura realista (que pretende ejercer la mímesis plena del mundo real), la literatura rosa, la literatura de aventuras, la literatura de vaqueros y la literatura policial (que pretenden ejercer la mímesis de un aspecto o tema específico del mundo real); también los géneros no representativos, como la poesía lírica.

Es necesario señalar dos puntos: 
a) Lo normal y lo insólito no son categorías fijas. Se trata de lo aceptado y de lo no aceptado socioculturalmente (sea en el plano natural o en el sobrenatural) por una comunidad determinada. Cada comunidad define lo normal y lo insólito a su manera. Por ejemplo, el Occidente actual no acepta la realidad de la magia, pero las tribus indígenas norteamericanas la consideraban como un elemento normal de su mundo. Este relativismo no sólo puede apreciarse entre diferentes comunidades, sino también dentro de una misma comunidad, tanto en el plano diacrónico como en el sincrónico.

En el plano diacrónico, los procesos históricos de cambio en una sociedad modifican irremisiblemente lo que ésta considera como normal y como insólito. Por ejemplo, los relatos maravillosos de estirpe cristiana (milagros de santos, apariciones del diablo, visitas al cielo y al infierno) y de estirpe folklórica (cuentos de hadas, duendes y brujas) eran aceptados como reales en el Occidente medieval, debido a las creencias sociales. En el presente es usual considerarlos irreales, debido a la secularización experimentada a partir del siglo XVIII.

En el plano sincrónico, dentro de una misma sociedad las creencias no son necesariamente homogéneas. Algunos grupos consideran ciertas nociones como reales, y otros como irreales. Es el caso del espiritismo, aceptado por sus seguidores pero rechazado por el resto de la sociedad. La literatura sobre la comunicación con los muertos es considerada realista por los espiritistas, y fantástica por los no espiritistas.

b) Es preferible la dicotomía normal/insólito a la dicotomía verosímil/inverosímil, ya que esta última no resulta adecuada para algunos de los géneros que estudiaré. Por ejemplo, muchas de las máquinas futuras descriptas en la ciencia ficción son verosímiles, ya que su desarrollo puede lograrse con el mero avance de la ciencia. Pero no son "normales" o "habituales" debido a que aún no existen en el mundo real. Lo mismo ocurre con la literatura de lo extraño: narra sucesos verosímiles, pero tan extraordinarios e infrecuentes que entran en la categoría de lo insólito.

Las literaturas de lo insólito se dividen en dos grupos: a) El insólito sobrenatural, caracterizado por la presencia de hechos sobrenaturales, y que engloba dos géneros: la literatura fantástica y la literatura maravillosa. b) El insólito natural, caracterizado por no incorporar hechos sobrenaturales, y que engloba dos géneros: la ciencia ficción y la literatura de lo extraño. Este planteo, basado en la presencia o ausencia de elementos sobrenaturales, permite una distinción ontológica esencial, ya que define dos formas opuestas de ver el mundo: la mágico-religiosa y la racionalista.

El insólito sobrenatural puede dividirse en dos categorías: la que presenta en forma problematizada los hechos sobrenaturales (literatura fantástica) y la que los presenta en forma no problematizada (literatura maravillosa). El insólito natural, en otras dos categorías: la que recurre a la ciencia y la tecnología para crear el hecho insólito (ciencia ficción) y la que no recurre a ellas (literatura de lo extraño): 


\begin{tabular}{|c|c|c|}
\hline \multicolumn{3}{|l|}{ Lo normal } \\
\hline \multirow{4}{*}{ Lo insólito } & \multirow[t]{2}{*}{ Natural } & Tecnológico (ciencia ficción) \\
\hline & & No tecnológico (lo extraño) \\
\hline & \multirow[t]{2}{*}{ Sobrenatural } & Problematizado (fantástico) \\
\hline & & No problematizado (maravilloso) \\
\hline
\end{tabular}

Antes de proseguir, será útil definir el aparato conceptual. Distinguiré tres categorías a utilizar:

1) Género. Es un conjunto de textos que comparte ciertas características formales y temáticas. Tales textos pueden tener un origen común o diverso, siempre que cumplan con las características formales y temáticas antedichas. Por lo tanto, es una categoría de carácter general y, hasta cierto punto, atemporal (puede hablarse de una literatura fantástica occidental y de una literatura fantástica china, aunque sus orígenes y sus devenires hayan sido independientes). En el caso de las literaturas de lo insólito, existen cuatro géneros: el fantástico, la ciencia ficción, el maravilloso y la literatura de lo extraño.

2) Corriente literaria. Es un conjunto de textos que comparte ciertas características formales y temáticas, y que tiene un origen y una genealogía comunes. Se diferencia del género en su mayor dependencia del contexto histórico para su delimitación (lo que implica una mayor homogeneidad). Entre los ejemplos figuran la narrativa gótica, el realismo mágico, la utopía y la fantasía heroica.

Un género puede englobar en bloque varias corrientes literarias. Así, la literatura maravillosa engloba por completo al realismo mágico. Pero también puede englobar ciertos textos de una corriente literaria, excluyendo otros. ${ }^{1}$ Por ejemplo, la novela gótica tiene dos etapas: la inicial, donde el elemento insólito es de naturaleza sobrenatural (por ejemplo, El castillo de Otranto de Horace Walpole, donde se recurre a la presencia de un fantasma), y la tardía, donde el elemento insólito es de naturaleza científica (por ejemplo, Frankenstein o El moderno Prometeo de Mary Shelley, donde se recurre a la biología). La primera etapa pertenece a la literatura fantástica; la segunda, a la ciencia ficción.

3) Modalidad. Es un conjunto de textos de orígenes heterogéneos y sin características formales y temáticas definidas, pero vinculados entre sí debido a cumplir con una condición general determinada. Mientras que la cantidad de géneros y de corrientes literarias es limitada, la de modalidades es virtualmente infinita, porque también lo son las condiciones que pueden proponerse para la clasificación del hecho literario.

\footnotetext{
Esta es la razón por la que prefiero el término corriente literaria en vez de subgénero (que presupone una subordinación estricta al género en el cual se inscribe).
} 
Un ejemplo de modalidad es el rótulo literatura de aventuras. No tiene especificidad histórica (engloba textos de distintos períodos) ni temático-formal (engloba textos realistas, fantásticos, históricos, de piratas, de vaqueros, etcétera), más allá de la condición general de que debe narrar peripecias interesantes. Otro ejemplo es el rótulo literatura de terror. Es una categoría bolsa que abarca géneros y corrientes literarias muy diferentes en cuanto a su genealogía y a sus características formales (como las leyendas populares macabras, la novela gótica, el terror urbano contemporáneo, etcétera), vinculados sólo por la condición general del efecto de terror.

\section{LA LITERATURA MARAVILLOSA}

Durante la Edad Media predominó en Occidente una cosmovisión que aceptaba lo sobrenatural como un elemento de la realidad. La hegemonía de la religión católica causó que la existencia de Dios, de los ángeles, del diablo y de los milagros constituyera el dogma oficial, articulado en construcciones doctrinales tan complejas como la Suma teológica de Tomás de Aquino. Esto, en el plano popular, se aunaba a creencias sobrenaturales menos abstractas, como la magia, la adivinación y la taumaturgia. Se aceptaba la existencia de "otro mundo", de naturaleza espiritual, que originaba los hechos insólitos ocurridos en este mundo, de naturaleza material.

Como toda cosmovisión, tuvo su proyección en el plano literario, dando como resultado la literatura maravillosa. El género puede definirse como el conjunto de textos donde los acontecimientos insólitos son de carácter sobrenatural y coexisten sin conflicto con los acontecimientos normales del mundo natural. La presencia de milagros, intervenciones divinas, magia y seres fabulosos no es problematizada (es decir, no provoca sorpresa, extrañeza o incredulidad): se la toma como un elemento más de la realidad. Existen tres vertientes del género: el maravilloso religioso, el maravilloso folklórico y el maravilloso histórico (correspondientes, hasta cierto punto, a los tres estamentos de la sociedad medieval: el clero, el campesinado y la nobleza).

El maravilloso religioso es el caso más patente de que lo normal y lo insólito no son categorías fijas. Para una comunidad creyente, pertenece al ámbito de las literaturas de lo normal. Lo sobrenatural forma parte de la realidad aceptada por consenso social. En cambio, para una comunidad no creyente, dichas narraciones pertenecen a las literaturas de lo insólito. Los casos citables son numerosísimos: narraciones que tienen a Dios o al diablo como protagonista, relatos sobre milagros de santos o apariciones de ángeles, historias sobre el diablo y sus andanzas y artimañas, exempla moralizantes, visiones del paraíso o del infierno, etcétera.

El maravilloso folklórico desciende del animismo celta, mediado por la mitología grecolatina, con su creencia en criaturas intermedias entre lo estrictamente divino y lo humano (ninfas, nereidas, sílfides, ondinas), en metamorfosis corporales y en 
la hechicería. Combinado con elementos del cristianismo, dio origen en la Europa Medieval a una vasta serie de supersticiones: se aceptaba la existencia de la magia, los aquelarres, la adivinación, la taumaturgia, los seres intermedios entre el hombre y el animal (hombres lobo, vampiros), la acción benéfica o maléfica de hadas, duendes y gnomos, etcétera. Los textos de esta corriente circularon en forma oral, siendo recopilados por escrito en fecha tardía. Un ejemplo son las antologías de Perrault, Andersen o los hermanos Grimm.

El maravilloso histórico consta de aventuras de héroes, reyes y nobles, tanto reales como ficticios, en las que intervienen elementos sobrenaturales. Se enfrentan con seres fabulosos (dragones, arpías, gigantes), con el demonio o con magos. A veces éstos últimos intervienen de forma benéfica, ayudando al héroe por medio de su hechicería (transportándolo por el aire a un sitio donde es requerido, o haciéndolo dormir durante años con una poción). Los exponentes principales son las narraciones de los ciclos artúrico y carolingio, con antecedentes en épicas nórdicas como el Cantar de los nibelungos. Durante el renacimiento la tradición continuó en la novela hispánica de caballerías.

El maravilloso tuvo poca visibilidad literaria durante el siglo XVIII, debido a que la hegemonía del Iluminismo no resultaba propicia para un género que presuponía una cosmovisión sobrenaturalista. Sólo se destacan las refundiciones de fábulas hechas por Samaniego, Iriarte y otros autores, rotuladas como literatura infantil (es decir, literatura para un estado de desarrollo pre-racional).

En el siglo XIX, el interés del romanticismo por lo irracional y lo sobrenatural, así como por el folklore, generó un redescubrimiento de la literatura maravillosa. Los principales exponentes de este proceso fueron los filólogos alemanes dedicados a la recopilación de textos orales, como los hermanos Grimm. Sin embargo, el contexto era distinto del medieval: la Europa decimonónica estaba altamente secularizada y el maravilloso puro no resultaba verosímil, lo que le vedó ser relevante (por ese entonces, la posición hegemónica en la narrativa estaba ocupada por el Realismo). Su trayectoria en la literatura escrita se desarrolló en tres caminos heterogéneos: a) Algunos textos, como los de Grimm, Perrault y Andersen, lograron vigencia y continuadores gracias a su adscripción a la literatura infantil. Derivación tardía de esta corriente es Alice in Wonderland (1865) de Lewis Carroll. b) Otros fueron reelaborados por la "literatura culta" para que sus estructuras argumentales portasen sentidos muy distintos a los originales. Es el caso de Fausto (1808-1832) de Goethe y de Don Juan (1844) de Zorrilla. c) Otros fueron transformados en textos fantásticos. Los sucesos sobrenaturales no eran presentados de manera incuestionada sino ambigua, para que fuera imposible determinar si eran reales o meros delirios.

En el siglo XX, la literatura maravillosa tuvo un breve auge debido al realismo mágico latinoamericano, caracterizado por la inserción de hechos sobrenaturales en el contexto de narraciones por lo demás realistas, sin que generen sorpresa o extrañeza 
en los protagonistas. El caso emblemático es Cien años de soledad (1967) de Gabriel García Márquez.

\section{LA LITERATURA FANTÁSTICA}

La literatura fantástica es el género donde los acontecimientos insólitos son de carácter sobrenatural y coexisten en forma problematizada con los acontecimientos normales del mundo natural. La presencia de sucesos no explicables por la razón genera una situación conflictiva en el texto, ya que éste, tanto a nivel de los personajes como del sujeto de la enunciación, no los admite como elemento legítimo de la realidad. Esta situación conflictiva se concreta en la ambigüedad entre una interpretación natural (que los sucesos son producto de un delirio, de un sueño, de una suposición errónea o de una casualidad) y una interpretación sobrenatural (los sucesos son reales).

El género surge en el siglo XVII. El desarrollo de las ciencias, el empirismo filosófico, la generación de un saber laico en las universidades y el aumento del nivel cultural de la burguesía, provocaron una progresiva secularización sociocultural, y un consiguiente declive del irracionalismo mágico-religioso de estirpe medieval. ${ }^{2}$ Esto hizo que la literatura maravillosa entrara en crisis, ya que la presentación desproblematizada de elementos sobrenaturales resultaba inverosímil para la nueva mentalidad laica. El fantástico temprano tiene tres corrientes principales, derivadas de las que he estudiado en la literatura maravillosa. Son el fantástico religioso, el fantástico propiamente dicho y la novela gótica.

El fantástico religioso, proveniente del maravilloso religioso, se diferencia de éste en tres rasgos básicos: a) La generación de ambigüedad con respecto a la naturaleza de los sucesos sobrenaturales. En vez de presentarlos de una manera límpida e incuestionada, genera la duda de si son reales o de naturaleza onírica. b) El uso del humor (orientado tanto a la mera entretención del lector como a fines satíricos), ausente casi por completo en los textos anteriores, de intencionalidad educativa o moralizante.

2 Uno de los puntos en que resulta más claro este proceso de secularización es el constituido por las lecturas de la Biblia realizadas por las escuelas teológicas del Renacimiento y del Barroco. Durante los siglos XVI y XVII la validez del texto es relativizada: deja de ser la autoridad indiscutida, la inapelable fuente de certezas (como que es de origen divino), para ser cuestionada, de modo accesorio al principio pero luego en aspectos cada vez más centrales. Los teólogos protestantes, en especial, llaman la atención sobre los puntos oscuros y las contradicciones del discurso bíblico, condenan las rígidas prescripciones morales del Levítico y de otros libros del Antiguo Testamento, privilegian la coherencia del sentido a expensas de la literalidad e impugnan los errores flagrantes (por ejemplo, aquellos pasajes donde se afirma que el Sol gira alrededor de la Tierra). Es un reemplazo del respeto devoto hacia la palabra divina por un acercamiento más cuestionador, que da importancia a los descubrimientos de la ciencia y de la filosofía. La Biblia ya no es el fundamento último del sentido, la instancia legitimadora de todo saber y toda certeza: esa posición pasa a ser ocupada por la observación metódica del mundo externo. 
c) La restricción del abanico temático: mientras el maravilloso religioso cultivaba los relatos hagiográficos, las apariciones de ángeles o demonios y las historias de trasmundo, el fantástico religioso sólo se dedicará a los dos últimos temas. Un ejemplo es "El sueño de las calaveras" (circa 1607-1612) de Quevedo, un relato de trasmundo donde el protagonista, sugestionado por la lectura de Dante, tiene una pesadilla en la que asiste al Juicio Final. No es un sueño profético inspirado por la divinidad, sino algo ambiguo, interpretable parejamente como un delirio causado por una lectura aterradora o como una auténtica revelación.

En el siglo XIX abundan los ejemplos. Entre los relatos de trasmundo, figura el anónimo argentino "Fantasmagoría" (1878), que narra en tono jocoso las andanzas de un alma que consigue salir de la cárcel del cuerpo y visita el infierno, el purgatorio y el paraíso, hallando en todos elementos para la sátira. Finalmente, como estos ámbitos no le agradan (lo que ilustra sobre la crisis del paradigma religioso), decide retornar al mundo físico. Entre los textos sobre apariciones de ángeles o demonios, destacaré "La doble vista" (1875) de Verón, donde un hombre que ansía la capacidad de leer la mente es visitado por Satanás, quien le concede su deseo. En vez de derivar hacia las consecuencias funestas del pacto demoníaco, como sería esperable en un texto maravilloso, el relato se dedica a las consecuencias humorísticas de la posesión de ese poder.

El fantástico propiamente dicho deriva del maravilloso folklórico. Utiliza sus mismos temas (espectros, vampiros, metamorfosis, hechicería, seres intermedios entre el hombre y el animal, etcétera), sólo que de modo problematizado, a través de un efecto de ambigüedad entre una lectura sobrenatural y una natural. En este subgénero la importancia de la ambigüedad es mayor que en el fantástico religioso, donde el objetivo era una mera descalificación lúdica de la autenticidad de los hechos sobrenaturales narrados. En el fantástico propiamente dicho, la ambigüedad se transforma en una estrategia narrativa, destinada a causar suspenso e interés en el lector. Un texto temprano es "La posada de mal hospedaje" (1604) de Lope de Vega. Un viajero se aloja en una posada, pero durante la noche lo acosan fantasmas que juegan a las cartas y lo amenazan con un hacha. Por la mañana el viajero encuentra todo intacto, y se pregunta si lo sucedido fue una pesadilla o si los espectros ordenaron la habitación antes de desvanecerse. Lo maravilloso folklórico (los fantasmas) aparece cuestionado: el texto se resiste a aceptarlo como realidad y propone una alternativa racional: que haya sido una mera ilusión. Es un contraste pleno con la visión llanamente mágica del hombre medieval.

En el siglo XIX, el fantástico propiamente dicho se independiza progresivamente de sus raíces folklóricas, adoptando temas abstractos y filosóficos. Aún así, sigue siendo frecuente el recurso al acervo popular, como en La Venus de Ille (1837) de Mérimée, donde un hombre a punto de casarse coloca distraídamente su anillo en el dedo de una estatua femenina. La estatua aparece en su lecho nupcial, donde lo abraza hasta 
destrozarlo. Es la adaptación de una leyenda oral italiana del siglo XII.

El fantástico histórico, finalmente, deriva del maravilloso histórico. Este último había entrado en crisis hacia finales del siglo XVI debido a la inverosimilitud de sus elementos sobrenaturales. Una muestra de este desgaste es Don Quijote (1605-1615) de Cervantes, donde se opone paródicamente el mundo de los caballeros andantes, ayudados por magos benefactores y acosados por magos hostiles, enamorados de doncellas encantadas, enfrentados a gigantes, dragones y espectros, bebiendo elixires que sanan instantáneamente sus heridas y transportados de un lugar a otro por medio de la magia, con el mundo prosaico de la España del siglo XVII.

Por consiguiente, la literatura sobrenatural relativa a la nobleza experimentó un cambio. La novela de caballerías reflejaba una visión todavía medieval de esta clase social, presentándola en ocupaciones bélicas y realizando hazañas en territorios lejanos. La nueva corriente adoptó una visión de la aristocracia más acorde con la época, retratándola como terrateniente, viviendo sin guerrear en sus castillos y limitada al recuerdo de sus glorias pasadas. El fantástico histórico, consecuentemente con este paso de una ambientación de espacios abiertos y propicia para la épica a una de espacios cerrados y centrada en la decadencia (paradigmáticamente, un mohoso castillo), troca el énfasis en la aventura por el énfasis en lo macabro.

Esta nueva corriente, la novela gótica clásica, no surgió inmediatamente de las ruinas de su antecesora. Hubo un período intermedio durante finales del siglo XVII y principios del XVIII donde proliferaron las novelas sobre nobles que incluían ciertos contenidos de magia y hechicería, como The Adventures of Ferdinand Count Fathom (1752) de Tobías George Smollet. También abundaron las narraciones sensacionalistas sobre crueles aristócratas que realizaban crímenes espeluznantes en la soledad de sus castillos, como Horrid Mysteries (1757) de Karl Grosse y Longsword, Earl of Salisbury. An Historical Romance (1762) de Thomas Leland.

El texto que inicia el gótico es The Castle of Otranto. A Gothic Novel (1764) de Horace Walpole, donde un perverso noble mata a su hijo y repudia a su esposa. Comienzan a observarse fenómenos inexplicables: aparecen fragmentos de una gigantesca armadura, los retratos cobran vida, un rayo destruye el castillo y, finalmente, el gigantesco espectro del antiguo rey surge de las ruinas y asciende al cielo. Escarmentado, Manfredo se retira a un monasterio. La obra, a diferencia de la novela de caballerías, presenta el elemento sobrenatural de forma problematizada: excepto en el desenlace, los protagonistas se resisten a creer que los sucesos son obra de un espectro, achacándolos tanto a la casualidad como a un intruso oculto.

Hacia fines del siglo XVIII y principios del XIX, se produjo el enfrentamiento de dos escuelas literarias, cada una de ellas ligada a una definida posición filosófica. Por un lado, el Neoclasicismo, caracterizado por la mesura, el equilibrio formal, el uso de temas grecolatinos y el énfasis en el orden y en la racionalidad. Su trasfondo filosófico fue el 
Iluminismo, cristalización definitiva de un largo proceso de secularización iniciado en el renacimiento. Sus rasgos principales fueron el racionalismo, el empirismo y la crítica del oscurantismo religioso. El universo era interpretado como un vasto mecanismo regido por leyes susceptibles de ser descubiertas, analizadas y cuantificadas por medio de la razón. Por otro lado, el Romanticismo, caracterizado por el énfasis en el individualismo y el subjetivismo (lo que se oponía a la universalidad de la razón), la valoración de lo diferente y de lo distinto frente a lo cotidiano y común, la libertad estética y la no sujeción a moldes establecidos (consecuencia lógica del individualismo), el culto a la originalidad y a la personalidad renovadora, el uso de temas medievales (período desdeñado por los neoclásicos, que interesó a los románticos por considerarlo el momento de surgimiento de las nacionalidades europeas y por lo tanto de las idiosincracias propias de cada país, de nuevo en oposición a la universalidad dieciochesca). En especial, el rasgo del subjetivismo se proyectó en un amplio y profundo interés por lo irracional, tanto en lo relativo a los aspectos poco explorados de la conciencia (el sueño, el delirio, la exaltación provocada por las pasiones intensas, la locura) como a lo sobrenatural y misterioso.

Como resultado de este enfrentamiento entre el racionalismo secularista del Neoclasicismo y el irracionalismo sobrenaturalista del Romanticismo, el género fantástico experimentó una gran expansión debido a su presentación problematizada del hecho irreal. Al reelaborar de modo distanciado los temas maravillosos, al acceder a ellos con una mirada cuestionadora, constituyó el vehículo ideal para expresar la inquietud sobrenaturalista del Romanticismo.

Entre los principales autores fantásticos decimonónicos pueden mencionarse, en un brevísimo repaso, los norteamericanos Edgar Allan Poe y Nathaniel Hawthorne, el inglés Montague Rhodes James, los franceses Teóphile Gautier, Gerard de Nerval, Charles Nodier y Guy de Maupassant, el alemán E. T. A. Hoffmann y el español Gustavo Adolfo Bécquer.

\section{LA LITERATURA DE LO EXTRAÑO}

La literatura de lo extraño es el género donde los acontecimientos insólitos son de carácter natural y no pertenecen al ámbito de la ciencia y de la tecnología. Estos acontecimientos son perfectamente verosímiles pero, en función de un rasgo cualitativo como su peculiaridad y de un rasgo estadístico como su escasa frecuencia, salen del campo de lo normal.

Se trata de un género necesariamente difuso, ya que lo extraño (como lo fantástico) no es una categoría fija sino simplemente lo aceptado como tal por una sociedad determinada. Puede haber diferencias entre lo que dos sociedades distintas (por ejemplo, la occidental y la japonesa) consideren como extraño; lo mismo puede suceder en dos 
etapas de la misma sociedad (por ejemplo, las edades Media y Contemporánea en Occidente) o en una misma etapa de una misma sociedad (por ejemplo, en el caso de distintas subculturas, o incluso de distintos individuos).

Es factible una distinción basada en la ubicación textual del acontecimiento. En primer lugar, las obras donde lo extraño figura en el plano del discurso. Es el caso de "Instrucciones para subir una escalera" de Julio Cortázar, que al describir un acto cotidiano con minuciosidad extrema y con el estilo de un folleto instructivo, consigue impregnarlo con una atmósfera inquietante. En segundo lugar, las obras donde lo extraño figura en la psicología o en el punto de vista de los personajes. Un ejemplo es "Algunas peculiaridades de los ojos" de Philip Dick, donde un hombre lee un libro tomando las metáforas en sentido literal: al encontrar frases como "sus ojos la acariciaron" y "no tiene entrañas", se aterra pensando que es la prueba de una invasión de extraterrestres con órganos autónomos. En tercer lugar, las obras donde lo extraño figura en el plano referencial (es decir, en los sucesos narrados). Es el caso de la mayor parte de los textos, como los de Ambrose Bierce y Edgar Allan Poe.

El género puede dividirse en tres corrientes: la literatura extraña propiamente dicha, la utopía clásica y la literatura de lo "real maravilloso".

La literatura extraña propiamente dicha está compuesta por textos que transcurren en un entorno no imaginario, rasgo que la distingue de la utopía. En algunos casos, este entorno es explícito; en otros, no se lo indica con marcas referenciales e incluso puede llegar a ser totalmente indeterminado (como en El proceso de Kafka). Sea como fuere, los textos nunca indican pertenecer a un ámbito no real. Entre los ejemplos de textos donde lo extraño está en el plano del discurso, figura, además del ya mencionado cuento de Cortázar, "La secta del Fénix" de Jorge Luis Borges, donde se describe de forma críptica un acto secreto practicado por gran parte de la humanidad a partir de cierta edad, que resulta ser el sexo.

Entre aquellos donde lo extraño reside en la psicología o en el punto de vista de los personajes, merece destacarse "Wakefield" (1835) de Hawthorne, donde sin motivo alguno un hombre se ausenta de su hogar durante veinte años, permaneciendo oculto en una pensión cercana y espiando ocasionalmente a su esposa, que con el paso del tiempo termina por considerarse viuda; una noche de lluvia, también sin que nada explique su decisión, regresa a su hogar como si sólo hubieran pasado unas horas.

Entre los textos donde lo extraño está en el plano referencial, figuran "Un descenso al Maëlstrom" y "El entierro prematuro" de Poe, donde circunstancias perfectamente verosímiles generan una atmósfera de extrañamiento y de horror. En el primer caso, un marinero cae en un enorme torbellino de las costas de Noruega y sólo logra salvarse tras una larga serie de padecimientos; en el segundo, un cataléptico es tomado por muerto: las circunstancias del enterramiento son descriptas de forma minuciosa por el inmóvil protagonista, que en ningún momento deja de estar consciente. 
La utopía (ou topos en griego significa no-lugar o lugar inexistente) es una corriente literaria cuyo objetivo es la construcción imaginaria de una sociedad. Propone un mundo alternativo al real, bajo la forma de una ficción narrativa consistente en el relato de un viaje a dicho mundo alternativo. Debe diferenciarse cuidadosamente utopía de utopismo. La utopía es un artefacto literario que funciona según invariantes coherentes, y cuya forma privilegiada es el viaje a una comarca lejana. El utopismo es una actitud mental, un modo de pensamiento, no caracterizado por una estructura formal definida. Ambos poseen un proyecto social y construyen, en oposición a la realidad, un mundo alternativo. Sin embargo, la utopía supone ciertos criterios filosóficos, estructurales, diegéticos y estilísticos. Los principales son:

1) Realismo. La utopía busca describir una sociedad que pueda llegar a ser posible, por lo que debe volverla verosímil. Esto la distingue del mundo al revés (por ejemplo, los poemas carnavalescos del siglo IV), que si bien mediante la vía del grotesco o la exageración genera una crítica de la realidad, exhibe una inverosimilitud que lo separa de una utopía sometida a imperativos de credibilidad.

2) Humanismo. La utopía es esencialmente humanista o antropocéntrica, ya que hace del hombre el dueño de su destino. Esto la distingue de los textos referidos a una "edad de oro", frecuentes en la Antigüedad y el Renacimiento, que provienen de un pensamiento teológico.

3) Tópico del viaje. El viaje, ya sea en el espacio o en el tiempo, es el principio narrativo estructurador de todas las utopías. Simbólicamente, representa el abandono de viejos valores, seguido del descubrimiento de valores nuevos. Ubica al viajero como un punto de vista exterior que encarna los valores puestos en discusión, siendo la travesía el elemento que crea la posibilidad de la novedad y del diálogo.

La corriente comienza con Utopía (1516) de Tomás Moro, relato de un viaje imaginario donde se descubre un país hasta entonces desconocido y que destaca por sus instituciones. Esta sociedad otra es diferente desde todo punto de vista de la sociedad real, e inmensamente superior (por ejemplo, hay libertad de cultos, la cantidad de horas de trabajo diario está delimitada, no se utiliza el dinero y no hay pobreza).

Finalmente, la literatura de lo "real maravilloso" es una corriente desarrollada en América Latina durante la segunda mitad del siglo XX. Mientras el realismo mágico incorporaba lo sobrenatural de modo no problematizado, esta corriente carece de todo tipo de elementos sobrenaturales. Consiste en una narrativa realista, pero centrada en una particular forma de ver lo real como algo extraordinario y "mágico" (uso este término en su acepción metafórica), destacando sus aspectos sorprendentes, improbables y pintorescos. Su principal representante es el cubano Alejo Carpentier. Tras una estadía en Europa, donde tomó contacto con las vanguardias, realizó una visita a Haití en la que contempló con ojos surrealistas la abigarrada realidad local. Esa visión distanciada (tanto por el acostumbramiento al ámbito europeo como por la implícita novedad de la perspectiva vanguardista) le permitió realizar una presentación de lo cotidiano como 
algo intrínsecamente extraño.

\section{LA CIENCIA FICCIÓN}

La ciencia ficción es el género literario donde los elementos insólitos son de carácter natural y pertenecen al ámbito de la ciencia y de la tecnología. Se diferencia de las literaturas maravillosa y fantástica por carecer de elementos sobrenaturales, y de la literatura de lo extraño por la índole de los elementos naturales descriptos (en este último género, no están vinculados a la ciencia y a la tecnología).

Como he expuesto, a partir del Renacimiento se produce en Occidente un conflicto entre dos visiones del mundo, la mágico-religiosa y la secular, que llega a su cenit a principios del siglo XIX con el choque entre el racionalismo de la Ilustración y el irracionalismo sobrenaturalista romántico. En ese período es posible apreciar, en ciertos géneros como la literatura fantástica, la literatura policial y la ciencia ficción, un intento de resolver la separación de paradigmas mediante el trazado de una articulación en el plano de la ficción. En la literatura fantástica, la forma de resolución de este antagonismo es la ambigüedad: el enigma es presentado de modo vago y difuso, a fin de que sea imposible determinar si se trata de un hecho sobrenatural o explicable mediante la razón. De los tres géneros, es el más cercano a lo mágico-maravilloso inicial, el menos marcado por la secularización, ya que lo irreal siempre está presente.

La literatura policial presenta un enigma indescifrable para los personajes, excepto para un detective cuya mente superior utiliza como recursos la lógica, la deducción y la lucidez (en una palabra, el método científico). Carece de elementos sobrenaturales, aunque en ocasiones, como "The Murders of the Rue Morgue" de Poe o algunos cuentos de Chesterton, se insinúa una explicación de esta clase con la intencionalidad narrativa de generar tensión y suspenso.

Finalmente, la ciencia ficción relata hechos insólitos otorgándoles plausibilidad a través de explicaciones científicas. Debe enfatizarse este hecho, ya que el género ha sido considerado a menudo como una subclase de la literatura fantástica, ${ }^{3}$ siendo que en realidad evita cuidadosamente las apelaciones a lo sobrenatural. Los elementos insólitos y apartados de lo cotidiano que aparecen en ella (como alienígenas o naves espaciales) no cuestionan la racionalidad, sino que son extrapolaciones más o menos audaces del pensamiento científico. Incluso en la ciencia ficción pesimista, que alerta sobre el progreso desmedido, la crítica a los frutos de la razón se hace desde un punto de vista también racional, sin que les sean contrapuestos elementos de orden mágico.

Dos rasgos básicos de la ciencia ficción son la presencia de máquinas o de referencias científicas y la ambientación futurista. La presencia de máquinas o de

3 Por ejemplo: Sternberg. 
referencias científicas no necesita plasmarse de modo explícito; en numerosos textos los elementos científicos aparecen implícitos o apenas insinuados. Un ejemplo paradigmático es "Green Brother" de Howard Waldrop, que narra un caso de telepatía en una comunidad de indígenas norteamericanos. Eso no es visto por los protagonistas como un avance biológico, sino que es interpretado dentro de su propio paradigma cultural, como una visión mágica. En la corriente literaria de la "fantasía heroica", que relata historias de magos, espadachines y hadas, los sucesos no se diferencian de los del cuento maravilloso, excepto en que se postula que los actos "mágicos" son producto de una tecnología tan avanzada que no necesita de existencia física (uno de sus rasgos podría ser, por ejemplo, la extrema miniaturización), y a la cual los personajes apenas comprenden (debido a que esta tecnología se desarrolló en un pasado remoto), manipulándola sólo con órdenes a las que creen frases mágicas. En otras palabras, la presencia del componente científico-tecnológico es un requisito imprescindible, pero no es necesario que esta presencia sea explícita, pudiendo tratarse simplemente de su gravitación implícita. Tal gravitación es factible de ser producida ya por alusiones crípticas del sujeto de la enunciación (como en Waldrop), ya por el trasfondo histórico de la propia corriente literaria (como en la fantasía heroica).

La ciencia ficción suele constar de narraciones que transcurren en el futuro. Pero es el status epistemológico de los hechos científicos en el contexto de enunciación, y no su ubicación temporal, lo que determina como ciencia ficción a la narración. No es necesario que el invento o descubrimiento ocurra en el futuro, sino que aún no exista en el mundo objetivo del autor y del lector. Por ejemplo, los relatos de Las fuerzas extrañas (1906) de Leopoldo Lugones no transcurren en 1950, sino en el tiempo en el cual fue escrito el texto. Lo que los define como ciencia ficción es que las invenciones que describen aún no existían en 1906. Otro ejemplo: Herbert George Wells escribió en 1903 "The Land Ironclads", que predice la utilización militar de máquinas blindadas provistas con cañones. El tanque fue inventado en 1916. Como Wells escribió su relato en 1903, es ciencia ficción; si lo hubiera escrito en 1920, no sería ciencia ficción (en otras palabras, su componente tecnológico sería parte de lo normal y no de lo insólito).

En el polo opuesto, un texto como Aeropuerto (1968) de Arthur Hayley no es ciencia ficción porque, pese a tratar un hecho propio de la ciencia y la tecnología (el aeropuerto), se trata de ciencia y tecnología existente en la época, lo que lo ubica en el plano de la literatura meramente realista. Al no tratarse de algo inexistente en el contexto de enunciación, no puede aplicarse la ficción creativa al hecho científico. Por lo tanto: los textos de ciencia ficción pueden transcurrir en el futuro, en el presente o en el pasado, pero deben narrar hechos científicos no concretados en el momento de la escritura de la obra. El hecho de que sea común la ambientación futurista se debe a que vuelve más plausible la presentación de elementos científicos desconocidos.

Pasando al plano histórico, durante los siglos XVIII y XIX la ciencia ficción no fue una entidad única y monolítica. Sólo se consolidó como tal hacia 1890-1900, 
en una fusión de cuatro corrientes previas, de orígenes sumamente heterogéneos. Es importante aclarar este punto porque prácticamente todos los panoramas críticos abordan la prehistoria del género como un proceso unificado, lo que genera errores de apreciación y distorsiones conceptuales. Por ejemplo, suelen citarse como precursores al anónimo Cantar de Gilgamesh, a Historia verídica de Luciano de Samosata, a Somnium Astronomicum de Kepler o a Los viajes de Gulliver de Swift. En ciertos casos se ha llegado a incluir en esta lista la Divina Comedia, las alfombras mágicas de Las mil y una noches o el episodio de Clavileño del Don Quijote. ${ }^{4}$

Eso es un ejemplo palpable de una crítica literaria que no examina el fenómeno textual desde una perspectiva histórica rigurosa, sino que aborda esos autores antiguos, renacentistas y decimonónicos a partir del punto de vista de la ciencia ficción contemporánea, con las deformaciones de apreciación que tales "anteojeras mentales" conllevan. Se lee la literatura del pasado con ojos del siglo XX o del siglo XXI. Es un fenómeno similar al descripto por Borges en "Kafka y sus precursores", cuando señala que percibimos ciertas obras de Melville, de Bloy y de Browning como antecesoras del estilo y de los temas de Kafka, pero que esa percepción se produce sólo a posteriori de la lectura de la obra del checo. La presencia de Kafka modela y altera el modo de ver las obras previas. Con la ciencia ficción ha ocurrido lo mismo: la crítica ha considerado como iniciadoras del género a obras que poco tienen que ver con él.

Propongo al respecto un modelo tomado de las ciencias biológicas. Cuando Linneo realizó en el siglo XVIII la primera clasificación sistemática de los organismos, se basó en un criterio morfológico consistente en agrupar las especies en distintos conjuntos (denominados, en jerarquía decreciente, reino, tipo, clase, orden, familia y género) según sus características físicas. Ese criterio era impresionista: dos organismos muy distantes entre sí podían haber asumido durante su evolución formas similares, por lo cual eran englobados en el mismo grupo. Es el caso del avestruz africano y del ñandú sudamericano, aves sin ningún parentesco que fueron incluidas en el grupo Ratites, constituido por las aves de gran tamaño incapaces de volar. En otros casos, los criterios para definir una familia de organismos eran totalmente distintos de los usados para definir otra familia, lo que acentuaba el carácter impreciso de la clasificación. Debido a esto, en tiempos recientes se ha sustituido en la ciencia taxonómica el criterio morfológico por el criterio genético, basándose en la filogenia evolutiva de los organismos. Así, especies similares en el plano físico pero alejadas en el plano evolutivo deben ser clasificadas en grupos separados. Ello permite que su ordenamiento taxonómico refleje el auténtico devenir de los organismos a lo largo del tiempo, permitiendo una comprensión de sus diferencias reales por sobre aparentes similitudes.

\footnotetext{
4 He tomado los ejemplos de ensayos como La novela de ciencia ficción (Ferreras); Ciencia ficción:
} mitología del siglo XX (Elliff) y Qué es verdaderamente la ciencia ficción (Ferrini). 
Este concepto puede ser aplicado con respecto a las corrientes literarias. Considero que una correcta clasificación de las mismas debe basarse en el hecho concreto de su evolución histórica y no en semejanzas superficiales, que en ocasiones han llevado a que se engloben en una misma categoría a textos muy distintos.

La ciencia ficción no existía como tal antes de fines del siglo XIX. La literatura con rasgos similares a la actual ciencia ficción que circulaba en la época no constituía un área textual unificada, sino que estaba dividida en cuatro corrientes. La primera está constituida por los llamados "viajes extraordinarios". Durante el siglo XVIII se desarrolló en Europa una literatura de aventuras para públicos juveniles que solía transcurrir en tierras remotas y desconocidas. Ejemplos paradigmáticos son Robinson Crusoe (1719) de Daniel DeFoe y Gulliver's Travels (1726) de Jonathan Swift. Sin embargo, en el siglo XIX esta literatura entró en crisis debido a la exploración de casi todas las comarcas del globo por viajeros como Cook (en Oceanía) y Burton, Speke y Livingstone (en África). Los autores se encontraron sin sitios inexplorados donde ubicar sus historias.

La solución fue que los textos recurrieran a artilugios mecánicos, que posibilitaban a los protagonistas llegar a sitios hasta entonces inaccesibles. Estas máquinas prodigiosas son la característica principal de las narraciones de "viajes extraordinarios", término que el editor Hetzel usó como título general de las obras de Julio Verne. Entre tales sitios figuran el fondo del mar, explorado con un submarino en Veinte mil leguas de viaje submarino (1870) de Verne y en Aventuras extraordinarias del sabio Trinitus (1867) de Aristide Roger; el planeta Venus, explorado con un cohete a reacción en Viaje a Venus (1863) de Achille Eyraud; regiones desconocidas de África, exploradas con un globo aerostático en Cinco semanas en globo (1863) de Verne, etcétera.

La segunda corriente está integrada por las utopías cientificistas. Continuadoras de la utopía clásica, surgieron a finales del siglo XVIII y alcanzaron su máximo desarrollo durante el XIX. Su rasgo distintivo es la presencia de elementos científicos insólitos y de una ambientación generalmente futurista. Mientras Moro podía situar su "ciudad ideal" en las costas de América y en un tiempo presente, ello ya no era posible en la época de Bellamy. Debido a la exploración completa del globo, la utopía decimonónica tuvo en la ambientación futurista el principal camino para situar de un modo plausible sus comunidades imaginarias. Además, dado que la función del género es la especulación acerca de una sociedad perfecta, se incorporan en sus descripciones adelantos técnicos, especialmente a partir de la Revolución Industrial, época en la que comenzó a resultar imposible concebir una sociedad superior que no tuviera un mayor desarrollo científico que la presente.

El exponente más temprano es El año 2440 (1771) de Louis-Sébastien Mercier. No sólo constituye el primer texto utópico situado en el futuro, sino que también es el primero en caracterizar ese futuro como un período signado por el progreso científico 
y tecnológico. Otros ejemplos de utopías cientificistas son las argentinas Buenos Aires en el año 4000 (1876) de José María de Alcántara, Buenos Aires en el año 2080 (1879) de Aquiles Sioen y En el siglo XXX (1891) de Eduardo de Ezcurra.

La tercera corriente es el Naturalized Gothic, etapa tardía de la novela gótica inglesa. Los temas fundamentales del gótico clásico eran de cuño fantástico: el muerto redivivo, los fantasmas, la actualización de leyendas folklóricas. A principios del siglo XIX, comenzaron a perder eficacia debido a su repetición, lo que hizo necesario reemplazarlos por otros más creíbles e inquietantes. El recurso elegido fue la ciencia. El efecto de horror se basaba en las consecuencias desastrosas de un experimento fallido, en el descubrimiento de un organismo monstruoso, en la muerte de un científico por hybrys debido a "haber intentado lo que al ser humano le está vedado", etcétera.

El texto inicial es Frankenstein (1818) de Mary Shelley, donde un médico une piezas de cadáveres para fabricar un hombre artificial, en una reelaboración cientificista del tema tradicional del muerto viviente. En el ámbito hispánico, obras como Memorias de un desenterrado: historia lúgubre (1872) de Antonio de San Martín, y Cuentos negros o Historias extravagantes (1874) de Rafael Serrano Alcázar. En ellas el horror tiene bases científicas (como catalepsia, hipnotismo o enfermedades deformantes). No faltan ejemplos argentinos, como "Las momias del Louvre o Los misterios de la antigüedad" (1854) de Camilo Duteil, o diversos relatos de Raimunda Torres y Quiroga.

La cuarta corriente está constituida por las narraciones inspiradas en los postulados de la teosofía y del esoterismo. Durante el siglo XIX y parte del XX no se consideraba a las ciencias ocultas y a la ciencia oficial como saberes enfrentados. Existía una especie de continuum ciencia/ocultismo: se pensaba que las ciencias ocultas incursionaban en terrenos del conocimiento aún no cartografiados por la ciencia oficial, y que serían explorados en algún futuro. Que las ciencias ocultas eran una vanguardia epistemológica que indagaba fenómenos aún no explicados, pero que supuestamente tenían una causa natural.

En buena medida, ello se debió a la pátina cientificista que Franz Mesmer (fundador del hipnotismo y de la curación magnética) y Allan Kardec (fundador del espiritismo) confirieron a sus teorías. En el período mencionado puede apreciarse un continuo esfuerzo de los cultivadores de estas corrientes de pensamiento por hallar comprobaciones materiales y pruebas que pudieran ser defendidas ante evaluadores imparciales, así como un intento de aproximar sus artículos y ensayos al estilo riguroso de los escritos científicos.

Esta corriente tuvo un notable peso en la narrativa del período 1830-1930, para luego perder importancia con el general declive del ocultismo. Un ejemplo típico es Viaje maravilloso del señor Nic-Nac (1875), de Eduardo Holmberg, donde el protagonista envía su espíritu al planeta Marte, según las directivas de un médium.

El autor que culmina la prehistoria del género y comienza su historia es Herbert 
George Wells (1866-1946). Sus textos constituyen una síntesis y una cristalización de los principales rasgos de las dispersas corrientes de la proto ciencia ficción. La máquina del tiempo, por ejemplo, toma de los viajes extraordinarios el concepto del artefacto prodigioso que permite llegar a sitios antes inaccesibles, de la utopía la especulación sobre la sociedad futura, y del gótico cientificista el horror causado por los hombres subterráneos. La única corriente no adoptada por Wells es la narrativa teosófica, debido a la perspectiva racionalista del autor y a su hostilidad hacia el ocultismo.

A partir de Wells, las cuatro corrientes reseñadas comienzan a menguar en dinamismo, asimiladas por la cada vez más difundida ciencia ficción. La única que ha sobrevivido hasta el presente, aunque con menor relevancia que en el siglo XIX, es la utopía. La razón es que ha sido utilizada por autores de la literatura convencional como vehículo para sus inquietudes sociológicas. Entre los casos más relevantes figuran Brave New World (1932) de Aldous Huxley, 1984 (1949) de George Orwell y Heliópolis (1965) de Ernst Jünger.

\section{ApÉNDice. LAS Literaturas DE LO INSÓLITO Y LA LITERATURA DE MASAS}

Un punto importante es la especificación de los vínculos entre los géneros mencionados y lo que ha dado en llamarse literatura de masas. A menudo la crítica los ha englobado en esta categoría marginada, ${ }^{5}$ lo cual ha afectado negativamente su valoración, así como su encuadre dentro de la literatura en general.

Las literaturas marginales (es decir, las que no forman parte del canon) pueden dividirse en dos grupos: a) Las marginales de modo programático. Es el caso de movimientos rupturistas como las vanguardias o la literatura underground. Se trata de una marginalidad relativa, pues el objetivo de estas corrientes es convertirse ellas mismas en el canon, desplazando al canon anterior. b) Las marginales de modo no programático. Son las literaturas producidas y consumidas por un público escasamente ilustrado. En este caso su marginalidad es absoluta, ya que no es buscada sino que surge de la rotulación impuesta por los principales actores socioculturales (la crítica, el público culto y las universidades).

Esta segunda categoría es susceptible de otra subdivisión:

a) La literatura popular o folklórica. Está formada por textos producidos principalmente en zonas rurales, y en menor grado en zonas urbanizadas: romances, cantares de gesta, villancicos, fábulas, cuentos de hadas y leyendas. A menudo son anónimos y de transmisión oral (por lo tanto el público consumidor puede no estar alfabetizado). Su origen suele ser antiguo, ya que son transmitidos de generación en

\footnotetext{
5 Ejemplo paradigmático son los artículos de Umberto Eco "Sobre la ciencia ficción" y "Nuestro monstruo cotidiano". Apocalípticos e integrados (350-362).
} 
generación.

b) La literatura de masas. Está constituida por textos producidos en zonas urbanas, con autor conocido y transmitidos por la imprenta. Tiene un período y un ámbito determinables de surgimiento: el siglo XIX europeo. Tres factores colaboraron para esto. En primer lugar, los progresos de la alfabetización aumentaron la cantidad de público. En segundo lugar, la revolución industrial generó un abaratamiento del proceso de impresión y de fabricación del papel, por lo que incluso las clases menos adineradas pudieron costear los textos. En tercer lugar, el ascenso económico de la burguesía provocó un nuevo fenómeno: el surgimiento del ocio, del tiempo libre, que era llenado con esparcimientos como el deporte y la lectura.

Esta ampliación del lectorado creó un amplio mercado para textos de rápido y fácil consumo (es decir, no demasiado exigentes en cuanto a la complejidad de la trama y del estilo, y generadores de placer y entretención a través de recursos como el suspenso, el horror o la descripción de aventuras). Entre los principales ejemplos se encuentran la ciencia ficción, la novela rosa, la novela policial, la novela gótica, la literatura de vaqueros, los folletines bandolerescos (como el Juan Moreira de Eduardo Gutiérrez), etcétera.

La literatura de masas despertó polémicas, especialmente a partir de la Primera Guerra Mundial. Umberto Eco, en Apocalípticos e integrados (1964), ha elaborado una lúdica clasificación de las posturas sostenidas al respecto: los intelectuales "apocalípticos", como Adorno y Horkheimer, ven a la literatura de masas como un ejemplo de la decadencia del arte occidental; los "integrados", entre los que figuran Vattimo, Enzensberger o el propio Eco, como una nueva y creativa corriente de expresión artística.

"Apocalípticos" como Horkheimer y Adorno, en ensayos como "La industria cultural", ${ }^{6}$ desarrollaron un enfoque acusatorio referente a la literatura de masas. Según ellos, se caracteriza por su mera condición repetitiva, por su tendencia a estabilizar sus procedimientos en lo ya conocido y probado. Es serial e iterativa (es decir, una novela policial, una novela rosa o una novela de vaqueros siguen el mismo patrón general), lo cual la identifica como producto de una industria, la mercantilista "industria cultural", y no de un impulso auténticamente artístico. El lector cifra su goce estético en el tranquilizador reconocimiento de la perduración del código: queda asociado lo formulaico y repetitivo con el placer, y se pierde toda posibilidad de renovación, de ruptura y de transgresión.

La capacidad de producir entretenimiento simple y no problematizado genera un consumo alienado con respecto a los problemas fundamentales del arte, de la sociedad y del hombre. El lector transita por un texto despojado de cuestionamientos

Adorno y Horkheimer. 
y problemáticas sociales, políticas, filosóficas y culturales, por un texto que acepta el mundo "tal cual es" sin proponer cambiarlo, por un texto centrado únicamente en las peripecias argumentales. La mera entretención (la distracción) se convierte en una evasión de la realidad. La literatura de masas, según este concepto, sería funcional al Poder: constituye un mecanismo de despolitización, aleja al público lector de las problemáticas humanas fundamentales, y lo mantiene satisfecho, sin estimularlo a ejercer su propio y libre pensamiento.

A esto deben agregarse rasgos como el maniqueísmo en la caracterización de los personajes (los "malos" son infatigablemente crueles, mientras que los "buenos" aspiran a la santidad) y el conservadurismo ideológico: la peripecia narrativa siempre confirma la moral social. Por ejemplo, en la novela rosa, la aventura sentimental apunta al desenlace matrimonial. En la ciencia ficción, las audacias científicas son castigadas con la muerte del inventor. En la novela policial, prevalece la justicia y el criminal es castigado.

Dejando de lado el hecho de que en las últimas décadas la crítica ha reivindicado abundantemente el rol de la literatura de masas, ${ }^{7}$ es necesario hacer algunas precisiones y distingos:

a) He definido el concepto literaturas de lo insólito como un supergénero que engloba diversos géneros, corrientes y modalidades literarias, como por ejemplo la literatura fantástica, la ciencia ficción, la utopía y el terror. De éstos, la utopía nunca ha sido considerada como literatura de masas, sino como un género culto e influyente, propio de la "alta literatura". El motivo, además de la existencia de cultores prestigiosos como Moro, Campanella o Bacon, es que su característica principal es la crítica al sistema social y político existente, y la postulación de modelos alternativos. Ello evita toda acusación de "escapismo" o de "conservadurismo".

b) La literatura fantástica ha experimentado oscilaciones en cuanto a su valoración. Durante el siglo XIX había una actitud ambigua: se la consideraba como extravagante y a veces disparatada, pero al mismo tiempo se respetaba su poder imaginativo y la maestría de autores como Hoffmann y Poe. Durante parte del siglo XX se la consideró escapista (y, por lo tanto, "poco profunda"). En la actualidad, gracias a autores como Borges y Cortázar, se la tiende a considerar canónica.

El factor que ha favorecido su presente revalorización es, además de la existencia de autores destacables, que a pesar de haber sido durante mucho tiempo un género relativamente marginal, en ninguna etapa de su historia perteneció a la literatura de masas. Nunca fue sometida a una producción masiva e industrial, y por lo tanto a una sistematización comercial de sus características.

c) La ciencia ficción tuvo una rica historia durante el siglo XIX. Abundaban los

Para un panorama de esta reivindicación, remito a: Abraham, Borges y la ciencia ficción, 16-17. 
cultores exitosos y respetados, como Julio Verne y Albert Robida, aunque no se los consideraba tan profundos y trascendentes como, por ejemplo, Víctor Hugo o Gustave Flaubert. Ya en el siglo XX, Wells conjugó éxito comercial y apreciación crítica, ${ }^{8}$ al igual que los posteriores Huxley, Lewis y Stapledon.

En 1926 se produjo un cambio: en Estados Unidos Hugo Gernsback fundó Amazing Stories, la primera revista dedicada exclusivamente a la ciencia ficción, orientada a un público formado por científicos y adolescentes. Pronto le siguieron revistas similares. Estas publicaciones cultivaron el subgénero denominado Space Opera. Constaba de aventuras de héroes y exploradores espaciales, ceñidas a los cánones tradicionales del folletín de capa y espada, con la salvedad de que los villanos eran alienígenas o seres mecánicos. Estaba ambientada en escenarios desmesurados (imperios galácticos, guerras estelares) y a menudo incluía elementos esotéricos. Era frecuente la repetición de argumentos, el maniqueísmo en la delineación de los personajes, el conservadurismo moral y la omisión de problemáticas trascendentes. Es decir, los rasgos típicos de la literatura de masas.

El rol de Gernsback en la historia del género ha sido discutido. Para algunos, fue el responsable histórico de convertir la ciencia ficción en un ghetto, convirtiendo los revolucionarios logros de los escritores europeos en una subliteratura dirigida al consumo masivo y al público juvenil. Para otros, fue simplemente un catalizador que contribuyó a la consolidación de un mercado.

En épocas recientes, con autores como Phillip Dick, Stanislaw Lem, James Ballard o los hermanos Boris y Arkadi Strugatsky, el género se ha librado del estigma de la literatura de masas. Las tramas eluden la repetición de modelos y están orientadas a un público adulto. Los planteos éticos suelen no ser convencionales (por ejemplo, el héroe puede no ser "bueno", y también puede no reflejar los ideales y aspiraciones de la comunidad de turno), así como los estéticos (el texto puede tender en el plano estilístico a recursos problematizadores, que cuestionen la noción de un logos integrado y sin fisuras - como el fragmentarismo y el uso de citas apócrifas-).

Por lo tanto, la ciencia ficción sólo durante un período de su historia ha sido englobable en la literatura de masas. Ello la distingue de otras vertientes narrativas, como la novela rosa o la de vaqueros, que siempre han pertenecido a esta categoría.

d) La literatura de terror, surgida (en su vertiente moderna) en el siglo XVIII, tiene una ilustre cronología que incluye autores como Radcliffe, Lewis, Shelley, Poe, Stocker y Lovecraft. Junto a ellos hay otros que realizaron una obra compleja y exigente literariamente, ajena a las convenciones que caracterizan la literatura de masas.

Su participación en ésta última comienza entre los años 1820-1850, con la difusión

8 Por ejemplo, The Gorgian Literary Scene (1938) de Frank Swinnerton dedica más espacio a Wells que a Joyce. 
en Inglaterra de los penny dreadfuls y los shilling shockers, cuadernillos y folletos macabros que tuvieron una audiencia mucho mayor que las auténticas novelas góticas. Toscos, repetitivos, con personajes esquemáticos y un estilo estereotipado, buscaban el impacto en el lector mediante golpes bajos como la descripción morbosa de crímenes sangrientos y mutilaciones. Algunos de estos textos eran resúmenes simplificados de las novelas góticas clásicas, donde se habían eliminado las descripciones psicológicas de los actantes y se habían intensificado los episodios violentos. El vínculo del terror y la literatura de masas continuó durante el siglo XX en las revistas pulp de los años treinta y cuarenta.

El terror, por lo tanto, ha tenido dos vertientes en los últimos doscientos años. Por un lado, la culta. Por otro, la de masas, producida en serie para el mercado de los folletos (durante el siglo XIX) y de las revistas pulp (siglo XX).

En resumen, antes de rotular un género como perteneciente a la literatura de masas, es imprescindible evaluarlo a lo largo de sus distintas etapas y de sus distintos subgéneros. De esta manera, se puede descubrir que la adscripción del terror o de la ciencia ficción a esta categoría es muy relativa, o que vertientes narrativas usualmente consideradas como "alta literatura" han pertenecido a ella en ciertas épocas. Es el caso de la novela histórica, que a mediados del siglo XIX experimentó un gran auge bajo las formas del folletín periodístico y del pliego suelto, con los truculentos novelones de Angelón y de Pérez Escrich.

\section{CONCLUSIÓN}

En el decurso de este ensayo he presentado una definición concordada de cuatro géneros: la literatura fantástica, la literatura maravillosa, la ciencia ficción y la literatura de lo extraño. Se trata de una tarea imprescindible, debido a que la bibliografía crítica sobre estos temas suele carecer de una base teórica firme y abarcativa (basta cotejar los principales textos teóricos sobre el tema para advertir las posiciones contrapuestas, las lagunas y la falta de un aparato conceptual y terminológico estandarizado).

Conjuntamente, he presentado un análisis del inconstante vínculo de las literaturas de lo insólito con la cultura de masas, con el fin de determinar con precisión el hecho de que sólo en algunos momentos de la historia de las primeras puede hablarse de una participación en las segundas. Espero, con esta contribución, haber delineado una herramienta útil a futuros investigadores.

\section{BiBLIOGRAFÍA}

Abraham, Carlos. Jorge Luis Borges y la ciencia ficción: particularidades de la asimilación de un género de la literatura de masas por la literatura canónica. 
Buenos Aires: Quadrata, 2005.

La literatura fantástica argentina en el siglo XIX. Madrid: La biblioteca del laberinto, 2013.

Las revistas argentinas de ciencia ficción. Buenos Aires: Tren en movimiento, 2013.

Adorno, Theodor, Max Horkheimer y otros. Industria cultural y sociedad de masas. Caracas: Monte Ávila, 1974.

Barrenechea, Ana María. "Ensayo de una tipología de la literatura fantástica”. Revista Iberoamericana XXXVIII/80 (1972): 391-403.

Eco, Umberto. Apocalípticos e integrados. Barcelona: Lumen/Tusquets, 1999.

Elliff, Osvaldo. Ciencia ficción: mitología del siglo XX. La Plata: Editorial Carlos Buiza, 1968.

Ferreras, Juan Ignacio. La novela de ciencia ficción: interpretación de una novela marginal. Madrid: Siglo Veintiuno, 1972.

Ferrini, Franco. Qué es verdaderamente la ciencia ficción. Madrid: Doncel, 1971.

Sternberg, Jacques. Une Succursale du fantastique, nommée science-fiction. París: Le Terrain Vague, 1958.

Todorov, Tzvetan. Introduction á la littérature fantastique. París: Seuil, 1970. 